\title{
Performance Testing of a Trace Contaminant Control Subassembly for the International Space Station
}

\author{
J. L. Perry \\ NASA George C. Marshall Space Flight Center
}

R. E. Curtis, K. L. Alexandre, L. L. Ruggiero, and N. Shtessel

Boeing Defense and Space Group

Copyright $@ 1997$ Society of Automotive Engineers, Inc.

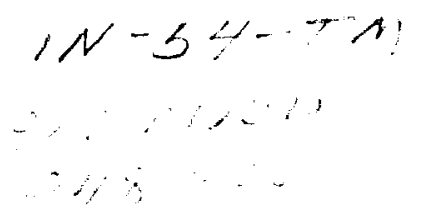

\begin{abstract}
As part of the International Space Station (ISS) Trace Contaminant Control Subassembly (TCCS) development, a performance test has been conducted to provide reference data for flight verification analyses. This test, which used the U.S. Habitation Module (U.S. Hab) TCCS as the test article, was designed to add to the existing database on TCCS performance. Included in this database are results obtained during ISS development testing; testing of functionally similar TCCS prototype units; and bench scale testing of activated charcoal, oxidation catalyst, and granular lithium hydroxide ( $\mathrm{LiOH})$. The present database has served as the basis for the development and validation of a computerized TCCS process simulation model. This model serves as the primary means for verifying the ISS TCCS performance. In order to mitigate risk associated with this verification approach, the U.S. Hab TCCS performance test provides an additional set of data which serve to anchor both the process model and previously-obtained development test data to flight hardware performance. The following discussion provides relevant background followed by a summary of the test hardware, objectives, requirements, and facilities. Facility and test article performance during the test is summarized, test results are presented, and the TCCS's performance relative to past test experience is discussed. Performance predictions made with the TCCS process model are compared with the U.S. Hab TCCS test results to demonstrate its validation.
\end{abstract}

\section{BACKGROUND}

In the early 1960 s, spacecraft air quality control mainly provided for odor control. Since that time, development of a TCCS suitable for supporting long duration space travel by humans has moved beyond basic odor control to a system-level approach for specifying and designing spacecraft contamination control systems. This development process is responsible for the TCCS design selected for deployment onboard the ISS. In addition, useful design and verification tools for TCCS processes have been developed. A summary of the ISS TCCS design and process simulation tool development is provided by the following discussion in addition to a brief summary of past TCCS testing.
TCCS DEVELOPMENT HISTORY - Air quality control onboard spacecraft has been a concern since space travel began. During the Mercury, Gemini, and Apollo programs, contamination control systems were simple and relied upon physical adsorption by activated charcoal. These systems were designed primarily for odor control.[1]

Unfortunately, expendable activated charcoal beds designed solely for odor control did not fully address the challenge of spacecraft cabin atmospheric quality. To address this challenge, several studies were conducted between 1965 and 1970 by Lockheed Missiles and Space Co, Inc. (LMSC) and the Hamilton Standard Division of United Aircraft Co. to investigate conceptual trace contaminant control system designs and advanced regenerative integrated life support system designs for spacecraft.[2-6] As a result of these studies, a system utilizing both activated charcoal adsorption and catalytic oxidation was established as the principle trace contaminant control system design approach for long duration space missions.

Between 1968 and 1975, LMSC conducted additional work on high temperature catalytic oxidation and activated charcoal adsorption which led to the development of a pre-prototype TCCS design. $[7,8]$ By 1975 , a prototype contamination control system had been built and tested by LMSC.[9] This prototype design is the basis for today's ISS TCCS.

ISS TCCS DESCRIPTION - The ISS TCCS is comprised of an activated charcoal bed, a high temperature catalytic oxidizer (HTCO), a granular lithium hydroxide ( $\mathrm{LiOH}$ ) bed, a blower, a flow meter, and an electrical interface assembly. Figure 1 shows a simplified process flow schematic of the TCCS and figure 2 shows a view of the flight hardware configuration.

Trace chemical contaminants are removed from the ISS cabin atmosphere by circulating air through the charcoal bed to remove high molecular weight contaminants and ammonia. More volatile, low molecular weight contaminants such as methane, hydrogen, and carbon monoxide are removed by the HTCO.

The HTCO is comprised of three primary parts - a recuperative heat exchanger, an electric heater, and a catalyst bed. It is designed to provide a high single pass methane oxidation efficiency. The heat exchanger assembly preheats the air as it enters the HTCO. Further heating is provided by the heater 
element. Final air heating occurs in the catalyst bed via radiation, conduction, and liberation of the heat of reaction from the oxidized contaminants.

The LiOH bed, located downstream of the HTCO, removes any acidic oxidation products that may be produced in the event that halocarbons break through the charcoal bed. It granular $\mathrm{LiOH}$.

The blower and flow meter maintain a steady flow rate of through the system that is sufficient to maintain individual trace contaminant concentrations below their respective spacecraft maximum allowable concentration (SMAC). The total flow is passed through the charcoal bed while only a portion flows through the HTCO and $\mathrm{LiOH}$ bed. The split flow combines downstream of the $\mathrm{LiOH}$ bed before exhausting from the TCCS. Three sample ports are provided at the charcoal bed inlet, charcoal bed outlet, and the LiOH bed outlet.[10]

\section{TCCS PERFORMANCE VERIFICATION}

Verification of the TCCS's contamination control performance has been based upon extensive testing and process model development. The following discussion provides a summary of past TCCS performance testing, the successful development of a TCCS process model, and the approach selected for verifying the ISS TCCS performance before flight.

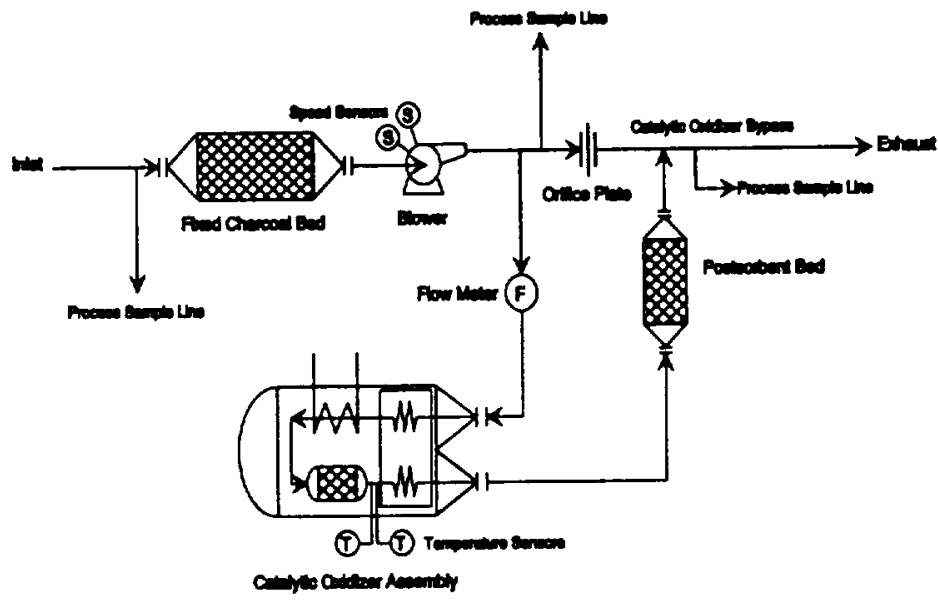

Figure 1. TCCS Process Flow Diagram

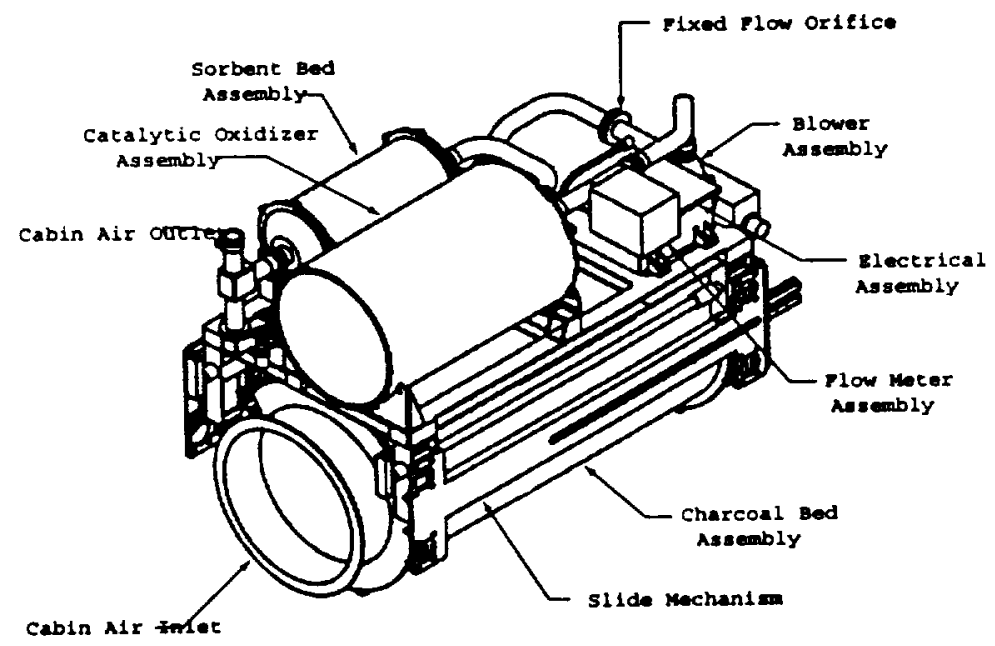

Figure 2. ISS TCCS Flight Configuration
PERFORMANCE TESTING EXPERIENCE - Performance data for functionally similar TCCS units having a ISS flight-like hardware geometry have been collected beginning with the first prototype built by LMSC. In late 1973, the first integrated prototype testing, during which the TCCS was challenged with a contaminant load, began. This test continued for 241 days and was completed in mid-1974. A follow-on test lasting 373 days was conducted between late 1974 and late 1975 to investigate high temperature catalyst poisoning. This test used the same catalyst batch that had been used in the 241 day test. Both of these tests successfully determined that the prototype TCCS design could maintain atmospheric contamination concentrations below specified maximum allowable levels.[11]

Additional TCCS prototype testing conducted between 1985 and 1997 by NASAMMSC has confirmed the results observed during the earlier LMSC tests. Included in the NASA/MSFC space station development test series are 4 integrated atmosphere revitalization tests, a 749-day life test, and a system-level contaminant challenge test.[12-18]

Also in support of space station development, functional pre-prototype and development TCCS units were built by LMSC. The pre-prototype unit was successfully tested by Boeing as part of a predevelopment atmosphere revitalization subsystem test. The development unit was tested successfully for 45 days by LMSC. $[19,20]$ Data collected during the LMSC development test were used as the most recent TCCS process model validation basis.

A substantial amount of bench scale performance testing of activated charcoal, catalyst, and $\mathrm{LiOH}$ has been conducted as part of the TCCS development.[21-25] Data from these tests have been used to refine the TCCS process model.

PROCESS MODEL DEVELOPMENT - In addition to TCCS hardware concepts, computerized techniques for designing and modeling the TCCS process were also under development between 1968 and 1975. A key product of this developmental work was establishing the adsorption potential theory as a design and performance simulation tool for fixed activated charcoal beds.[26] Its use for charcoal bed design and process modeling was based upon work reported by $W . K$. Lewis in 1950. This work demonstrated the utility of the adsorption potential theory for predicting adsorption isotherms without collecting large quantities of adsorption equilibrium data. [27] Such a tool was found to be very useful because it can lower the cost of design and development by reducing the need for expensive integrated TCCS testing.

Based upon this early work, the first generation of the Trace Contaminant Control Simulation Computer Program (TCCS-CP) was developed and released in 1975. This early version of the TCCS computerized process model was used by LMSC to analyze prototype TCCS design performance. $[28,29]$

By early 1977, LMSC developed a more complex, systemlevel version of the TCCS-CP. Spacelab contamination control system test data were used to validate this version of the process model.[30, 31] Comparisons between test data and performance predictions made by the process model showed good correlation in most cases. [32, 33] In late 1977, a modified version of the TCCS-CP was released as a generalized contamination control system model.[34] Between 1977 and 1986, this version, and slight variations of it, were used by the NASAMSFC and 
McDonnell Douglas Space Systems for Spacelab mission preflight contamination control system performance analyses.

Between 1986 and 1995, improvements were made to the TCCS-CP by both LMSC and NASA/MSFC. During this time, the TCCS-CP served as a primary engineering analysis tool for the Spacelab Program and was becoming increasingly important in the development of the ISS TCCS. LMSC made improvements that allowed for more user-friendly input data manipulation, improved runtime user interfaces, and program execution on a personal computer.[35]

Jointly, LMSC and NASA/MSFC developed enhanced input and output data manipulation capabilities, improved the routine for humidity condensate absorption, included catalytic oxidation poisoning effects relating to methane removal, and changed the basic charcoal loading equations based upon the latest bench-scale performance tests. The resulting process model is designated as the TCCS-CP Version 8.1.[36-38] This version of the TCCS-CP has been used extensively by both the Spacelab and ISS programs as a process simulation tool.

TCCS VERIFICATION APPROACH FOR ISS - The ISS Program chose to verify TCCS performance via analysis using the TCCS-CP Version 8.1. This approach, while less expensive, deviates from the traditional approach of verification by testing. Therefore, it contains an element of risk even though the process model has been validated against integrated TCCS development testing data.[39]

To address the perceived risk of this approach, the TCCS Performance Confirmation Test (TPCT) was defined. The TPCT was designed to provide the necessary data that would further validate the TCCS-CP, supplement the existing TCCS test database, and tie the process model's validation and previous development test results to flight hardware performance.

Although the TPCT is not a formal part of the TCCS design verification process, the data collected during its conduct serve the important function of minimizing the perceived risk associated with hardware verification by analysis.

\section{PERFORMANCE TEST OBJECTIVES}

The TPCT was designed to confirm the ability of the ISS U.S. Hab TCCS flight unit to control a specified contamination load at representative cabin environmental conditions. Specific objectives of the TPCT are the following:

1. To challenge the TCCS with a trace contaminant load representative of the ISS to confirm performance.

2. To obtain contaminant concentration versus time data for use in process model validation.

3. To compare the performance of the TCCS flight unit with performance observed during development tests.

\section{PERFORMANCE TEST DESIGN}

In order to properly confirm the U.S. Hab TCCS performance, the trace contaminant load and test volume atmospheric conditions must be defined. These parameters are central to the test design. The test volume atmosphere was required to be maintained between $18^{\circ} \mathrm{C}\left(65^{\circ} \mathrm{F}\right)$ and $27^{\circ} \mathrm{C}\left(80^{\circ} \mathrm{F}\right)$. Relative humidity was required to be $50 \pm 5 \%$. To prevent inward leakage of laboratory atmosphere into the test volume, it was required that the test volume pressure be maintained at a minimum of $3 \mathrm{~mm} \mathrm{Hg}$ over the prevailing barometric pressure.
To achieve the primary test objectives, a trace contaminant load based upon ISS design specifications was defined. This load is based upon the combined equipment offgassing from $75,000 \mathrm{~kg}$ of spacecraft hardware and the metabolic production of 5.25 crewmembers. The metabolic loading is based upon 4 people plus a 1.25 human metabolic equivalent for laboratory animals. Equipment and metabolic rates used to determine the test injection rates are listed by table 1 . The injection rates derived from the table $I$ equipment and metabolic rates were then adjustment to accommodate up to $0.23 \mathrm{~kg} /$ day $(0.5 \mathrm{lb} /$ day $)$ outward atmospheric leakage assuming that the TCCS provides $100 \%$ removal efficiency. $[40,41]$ The final test injection rates along are listed by table 2 .

Seven of the compounds included in the test load were considered to be of most interest. They are ethanol; dichloromethane; 1,1,2-trichloro-1,2,2-trifluoroethane (Freon 113); methane; acetone; carbon monoxide; and ammonia. These 7 compounds represent $63 \%$ of the total ISS design specification trace contaminant load. They also include the primary TCCS design drivers - dichloromethane, ammonia, methane, and carbon monoxide. Of the additional compounds listed in table 1, methanol is of most interest because of its potential for rapid activated charcoal bed breakthrough. The total test load represents $87.5 \%$ of the total ISS design specification load. This loading was also deemed manageable for the in-line gas sample analysis system to be used during the TPCT.

According to ISS performance specifications, the TCCS must maintain each individual contaminant's concentration below $90 \%$ of its respective SMAC. Table 2 also includes a listing of SMACs for the test compounds.

Table 1. ISS Equipment Offgassing and Metabolic Rates

\begin{tabular}{|c|c|c|}
\hline COMPOUND & $\begin{array}{c}\text { EQUIPMENT } \\
\text { RATE } \\
\text { (mg/kg-day) }\end{array}$ & $\begin{array}{c}\text { METABOLIC } \\
\text { RATE } \\
\text { (mg/man-day) }\end{array}$ \\
\hline ethanol & $7.85 \times 10^{-3}$ & 4 \\
\hline methanol & $1.27 \times 10^{-3}$ & 1.5 \\
\hline 2-propanol & $3.99 \times 10^{-3}$ & 0 \\
\hline n-butanol & $4.71 \times 10^{-3}$ & 1.33 \\
\hline toluene & $1.98 \times 10^{-3}$ & 0 \\
\hline xylene & $3.67 \times 10^{-3}$ & 0 \\
\hline chlorobenzene & $1.54 \times 10^{-3}$ & 0 \\
\hline dichloromethane & $2.15 \times 10^{-3}$ & 0 \\
\hline $1,1,2$-trichloro-1,2,2- & $1.89 \times 10^{-2}$ & 0 \\
\hline trifluoroethane & $1.41 \times 10^{-3}$ & 0 \\
\hline trichlorofluoromethane & $6.39 \times 10^{-4}$ & 160 \\
\hline methane & $3.62 \times 10^{-3}$ & 0.2 \\
\hline acetone & $6.01 \times 10^{-3}$ & 0 \\
\hline 2-butanone & $1.41 \times 10^{-3}$ & 0 \\
\hline 4 -methyl-2-pentanone & $6.62 \times 10^{-4}$ & 0 \\
\hline cyclohexanone & $2.03 \times 10^{-3}$ & 23 \\
\hline carbon monoxide & $8.46 \times 10^{-5}$ & 321 \\
\hline ammonia & & \\
\hline
\end{tabular}




\section{TEST CONFIGURATION SUMMARY}

The following summary provides a brief description of the TPCT facility, the integration of the test article with the facility and its control, and the analytical methods employed during the test. Detailed information on the test facility, test conduct, and test article restoration planning is provided by Reference 42 .

FACILITY DESCRIPTION - The Trace Contaminant Control Test Facility located in the Boeing-Huntsville Life Sciences Technology Center (LSTC) was used for conducting the TPCT. This facility was previously used to test a flightqualifiable Russian Mir TCCS.[43]

The test facility is comprised of a rack to control system atmospheric temperature, humidity, and chemical contaminant injection; a $9 \mathrm{~m}^{3}$ stainless steel mixing chamber; an in-line gas chromatograph/mass spectrometer (GC/MS) with a preconcentrator; and an in-line Fourier transform infrared (FTIR) spectrometer. These major components are interconnected by $5.1 \mathrm{~cm}$ (2-inch) electro-polished stainless steel tubing to create a closed air loop. The components were configured as shown by figure 3. The flight unit TCCS is mounted in its own transportation fixture. It is connected to the closed air loop via approved adapters.

The TCCS receives air from the system after it has been conditioned for temperature, humidity, and contaminant load. After processing by the TCCS, the air is directed back to the mixing volume. The entire system is a closed loop.

The test system is monitored for airflow, temperature, pressure, relative humidity, and contaminant load. Four sample ports are used to monitor the chemical composition of the test atmosphere. These ports are located at the TCCS inlet, downstream of the activated charcoal bed, downstream of the $\mathrm{LiOH}$ bed, and at the TCCS exhaust.
Table 2. Performance Test Contaminant Injection Rates

\begin{tabular}{|c|c|c|}
\hline COMPOUND & $\begin{array}{l}\text { SMAC } \\
\left(\mathbf{m g} / \mathbf{m}^{3}\right)\end{array}$ & $\begin{array}{l}\text { INJECTION } \\
\text { RATE } \\
(\mathrm{mg} / \mathrm{h})\end{array}$ \\
\hline ethanol* & 2,000 & 25.4 \\
\hline methanol & 9 & 4.3 \\
\hline 2-propanol & 150 & 12.5 \\
\hline n-butanol & 40 & 15.0 \\
\hline toluene & 60 & 6.2 \\
\hline xylene & 220 & 11.5 \\
\hline chlorobenzene & 46 & 4.8 \\
\hline dichloromethane* & 10 & 6.7 \\
\hline $\begin{array}{l}\text { 1,1,2-trichloro-1,2,2- } \\
\text { trifluoroethane* }\end{array}$ & 400 & 59.1 \\
\hline trichlorofluoromethane & 560 & 4.4 \\
\hline methane* & 3,800 & 37.0 \\
\hline acetone* & 50 & 11.4 \\
\hline 2-butanone & 30 & 18.8 \\
\hline 4-methyl-2-pentanone & 140 & 4.4 \\
\hline cyclohexanone & 60 & 2.1 \\
\hline carbon monoxide* & 10 & 11.4 \\
\hline ammonia* & 7 & 70.5 \\
\hline
\end{tabular}

- Primary test compounds comprising $63 \%$ of the ISS specification load.

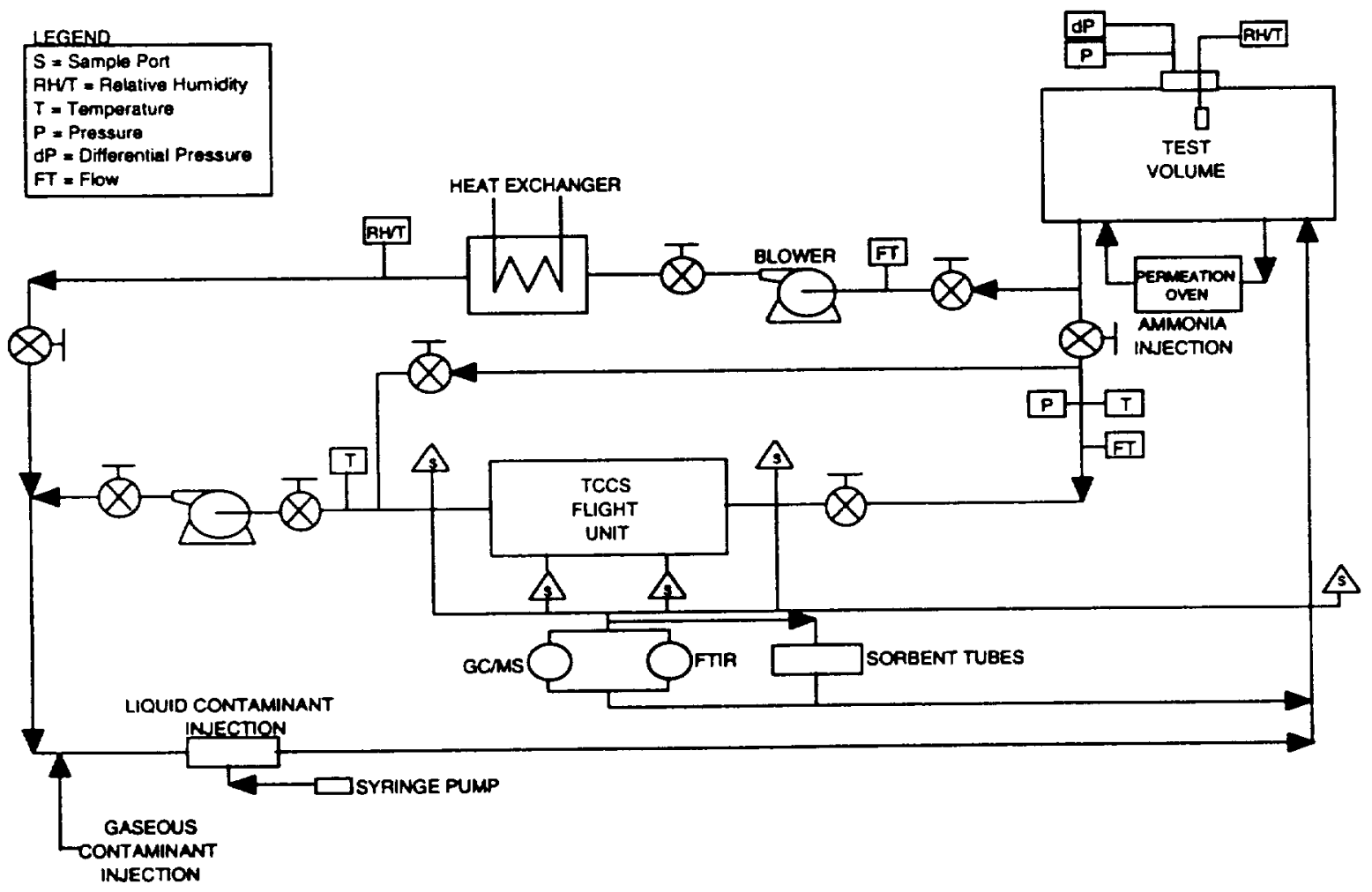

Figure 3. Simplified Test Facility Layout 
CONTAMINANT INJECTION - Both gaseous and liquid phase chemical contaminants were injected into the test chamber atmosphere during TCCS performance testing. Three methods were employed during the test. The following discussion provides a summary of each method.

Gaseous Contaminant Injection - Methane and carbon monoxide gases were supplied from separate pressurized bottles containing the following certified percentages of each contaminant:

\section{1. $14.98 \pm 0.01 \%$ methane/balance nitrogen}

2. $4.00 \pm 0.08 \%$ carbon monoxide/balance air

Methane and carbon monoxide injection was controlled by individual mass flow controllers with upstream pressure regulation.

Liquid Contaminant Injection - Liquid contaminants were injected as a single mixture. A syringe pump was programmed to pump the liquid mixture from a $10 \mathrm{~mL}$ glass vial to an injection port located on a heated bypass tube. The contaminants immediately evaporated upon injection and air flowing through the bypass tube swept them into the mixing chamber. The air from the mixing tank was then directed to the TCCS. The liquid contaminant vials were replaced daily, from Monday through Friday, to provide fresh stock solution during the data gathering phase of the test.

Ammonia Injection - Ammonia was injected continuously by a KIN-TEK Model 585-C precision gas standard generator. This unit dispensed a stable flow of pure ammonia directly into the mixing chamber. The permeation tube was refilled periodically to maintain a constant ammonia injection rate for the duration of the data collection period.

ANALYTICAL METHODS - Atmospheric sampling and analysis methods used during the test are the following:

1. Automated sample collection followed by analysis using in-line GC/MS and FTIR instruments.

2. In-line sample collection using gas detector tubes.

3. Sample collection into evacuated cylinders followed by off-line analysis by GCMS and gas chromatography (GC) instruments.

The in-line GC/MS system was comprised of a Hewlett Packard 5890 Series II GC and a Hewlett Packard 4972 mass spectrometer system (MS). The GC/MS was preceeded by an Entech Model 7000 preconcentrator. The automated GCMS system collected and analyzed one sample per hour.

The FTIR system was a MIDAC Model I2001 containing a 20 -meter constant volume gas cell that utilized a $0.5 \mathrm{~cm}$ mercury-cadmium-telluride (MCT) detector. The FTIR scan time per sample was approximately 3 minutes. The FTIR, like the GC/MS system, was completely automated.

Additional in-line analysis for ammonia and carbon monoxide was conducted as needed using detector tubes manufactured by Drager. This technique was used to verify concentration order of magnitude only.

Grab samples were collected periodically using evacuated cylinders to check in-line analysis results. These samples were analyzed off-line using several techniques. They included GCMS, GC combined with a flame ionization detector (FID) for methane analysis, and GC combined with either a thermal conductivity detector (TCD) or a helium ionization detector (HID) for carbon monoxide analysis.

INSTRUMENTATION AND CONTROL - The Command and Data Handling Subsystem (C\&DH) processes commands and monitors TCCS process parameters onboard the ISS via a level 3 multiplexer/demultiplexer (MDM). This hardware is in high demand by other agencies and, therefore, was not available for the TPCT. This was not a problem because the purpose of the test was to measure contaminant removal performance, not integrated system command and control. Therefore, the control system used during flight hardware acceptance testing was used.

To simulate the function of the level 3 MDM, a VAX system configuration was used. In this configuration, a Sorensen power supply provided 120-volts direct current (VDC) to the TCCS. Interface control and TCCS mechanical and electrical operational parameters were monitored with an Application Generator (AG) VAX Command and Control System. The AG VAX system provided an interactive TCCS animated display to interface with the test article. Key parameters such as HTCO temperature and flow rate, blower speed, and electrical power were monitored via the AG VAX animated display. These parameters were logged into a data acquisition system (DAS) database to facilitate post-test data reduction and analysis.

\section{PRETEST PERFORMANCE ANALYSIS}

A pretest TCCS performance analysis was conducted using the TCCS-CP Version 8.1 process model. This analysis served to bound the expected TCCS performance and to provide a preliminary performance baseline to which the actual performance observed during the test could be compared.[44] A brief summary of the pretest analysis approach and results is provided by the following discussion.

PRETEST ANALYSIS APPROACH - The pretest analysis employed two data analysis techniques. The first, called variables search, was used to determine the most significant process and simulation variables. [45] Those variables that most directly affect activated charcoal loading were investigated using this technique. Based upon the variables search analysis, the most significant variables were found to be contaminant liquid molar volume, TCCS flow rate, and relative humidity.

A final set of performance simulations were then conducted using design of experiments/robust design (DOE/RD) techniques.[46-48] The set of simulations conducted using the DOE/RD approach allowed for a pretest prediction of the 95 percent confidence interval range for each contaminant's concentration based upon the allowable variations in the test chamber atmosphere and TCCS process operations.

PREDICTED PRETEST PERFORMANCE - Based upon the series of pretest process simulations, it was predicted that methanol, dichloromethane, and ethanol would be the contaminants that would most likely saturate the charcoal bed. Methanol breakthrough was predicted as early as 9 hours and as late as 26 hours into the test. Dichloromethane breakthrough was predicted as early as 56 hours and as late as 394 hours after test startup. Breakthrough of ethanol may be observed as early as 411 hours and as late as 927 hours after test startup. Predicted nominal concentrations and the range associated with the pretest analysis $95 \%$ confidence interval are summarized by Table 3. 
Table 3. Pretest Performance Prediction Summary

\begin{tabular}{|c|c|c|}
\hline COMPOUND & $\begin{array}{c}\text { PREDICTED } \\
\text { RANGE } \\
\left(\mathbf{m g} / \mathbf{m}^{\mathbf{3}}\right)\end{array}$ & $\begin{array}{l}\text { NOMINAL } \\
\text { LEVEL } \\
\left(\mathbf{m g} / \mathbf{m}^{\mathbf{3}}\right)\end{array}$ \\
\hline ethanol & $1.4-2.1$ & 1.7 \\
\hline methanol & $0.78-1.17$ & 0.94 \\
\hline 2-propanol & $0.68-1.01$ & 0.81 \\
\hline n-butanol & $0.82-1.22$ & 0.98 \\
\hline toluene & $0.34 \cdot 0.50$ & 0.41 \\
\hline xylene & $0.62-0.93$ & 0.75 \\
\hline chlorobenzene & $0.26-0.39$ & 0.32 \\
\hline dichloromethane & $0.37-0.55$ & 0.44 \\
\hline $\begin{array}{l}\text { 1,1,2-trichloro-1,2,2- } \\
\text { trifluoroethane }\end{array}$ & $3.2-4.8$ & 3.9 \\
\hline trichlorofluoromethane & $0.24-0.36$ & 0.29 \\
\hline methane & $7.1-10.5$ & 8.4 \\
\hline acetone & $0.62-0.92$ & 0.74 \\
\hline 2-butanone & $1.0-1.5$ & 1.2 \\
\hline 4-methyl-2-pentanone & $0.24-0.36$ & 0.29 \\
\hline cyclohexanone & $0.11-0.17$ & 0.14 \\
\hline carbon monoxide & $2.1-3.1$ & 2.5 \\
\hline ammonia & $3.8 \cdot 5.7$ & 4.6 \\
\hline
\end{tabular}

\section{PRETEST CHECKOUT SUMMARY}

TEST VOLUME LEAKAGE - The system volume is approximately $9 \mathrm{~m}^{3}$ including the mixing chamber and associated support system plumbing. The allowable system leakage was established at $0.23 \mathrm{~kg} /$ day $(<0.5 \mathrm{lb} /$ day $)$. After the TCCS was installed in the system, the complete integrated system leakage as measured by pressure decay was found to be approximately 13.6 grams/day $(0.03 \mathrm{lb} /$ day $)$.

CONTAMINANT STABIITY - Understanding the background contamination level and the interaction of the test contaminants with the internal surfaces of the test facility were considered to be highly important to conducting a test of this nature. Pretest efforts to develop this understanding and its relationship to test bias are provided by the following summary.

Background Contamination - Before starting the test, a general chemical contaminant background check of the test rig was conducted. This investigation lasted several days and included, but extended beyond, the contaminants introduced during the test period. The primary instruments were the in-line GCMS and FTIR used during testing. There were no extraneous contaminants found using the ion identification and search capability with a library of over 300,000 compounds. By including the test contaminant detection limits as a quantitative value, the total background was found to be $1.5 \mathrm{mg} / \mathrm{m}^{3}$. If those contaminants which were found to be less than their respective detection limits are not included, then the background was approximately $0.22 \mathrm{mg} / \mathrm{m}^{3}$. The maximum allowable background contamination was $3.5 \mathrm{mg} / \mathrm{m}^{3}$.
System Bias and Adsorption by System Walls -Before installing the TCCS in the test stand, a test of contaminant adsorption by the internal surfaces of the test rig was conducted. This was accomplished by injecting known quantities of the test contaminants into the test chamber and monitoring their concentration over time.

The liquid phase contaminants were injected as a composite mixture with a syringe pump in order to emulate the injection process to be used during the TPCT. Pre-determined quantities of methane and carbon monoxide were injected continuously from pressurized gas bottles. A discrete amount of ammonia was continuously injected as a gas via permeation tube. The expected concentrations are based on the contaminant mass injected and known system volume and pressure. Average steady state concentrations were measured as well as mean standard deviations and associated $95 \%$ uncertainties using tfactors. System biases were determined by subtracting the observed concentrations from their respective target values.

A wide range of system biases was observed, from $-36 \%$ of target for toluene to $+48 \%$ for trichlorofluoromethane. Negative bias in the range of $30-37 \%$ of the target amount was observed for n-butanol, 4-methyl-2-pentanone, toluene, chlorobenzene, o-xylene, and cyclohexanone. Subsequent analyses using an off-line method did not show the same bias, so this was not attributed to system adsorption but was determined to be an artifact of the in-line trapping mechanism. As such there was no observed system adsorption.

The above system biases were ultimately used in the final data reduction when establishing the relationship between projected tank concentration and observed steady state concentration.

System Purge and Flow Balancing - Prior to the start of contaminant injection, the TCCS was installed online and was purged with TOC grade air. This was done to establish nominal functionality of the test article and to set valve positions for flow rate through the unit.

\section{TESTING SUMMARY}

The TPCT began on 19 January 1998 . The TCCS operated continuously until the test was completed on 14 February 1998. The overall test duration was 624 hours and all of the primary test objectives were satisfied. A summary of the TCCS and facility operations during the TPCT are provided by the following discussion. A brief assessment of the overall TPCT operations is also provided.

TCCS OPERATIONS - Throughout the test, the TCCS operated flawlessly. Inlet air flow and HTCO temperature were maintained at steady levels. The HTCO flow rate adapted to the total system pressure to provide almost a constant command voltage to the flow meter by adjusting the blower speed.

FACILITY OPERATIONS - The facility provided a closed loop which provided air to the TCCS within the required conditions summarized by Table 4 . The average test conditions were the following:

1. Air temperature of $22.5^{\circ} \mathrm{C}\left(72.5^{\circ} \mathrm{F}\right)$

2. Relative humidity of $50.4 \%$

3. System pressure of $760 \mathrm{~mm} \mathrm{Hg}$.

Test operations anomalies were very few and minor. During two test days, it was found that the liquid contaminant in- 
jection system was leaking. It was repaired and normal injections resumed. Also, one ammonia permeation tube dried up prematurely; however, it was replaced with minimal impact to the test operation. Adjustments were required to the $\mathrm{CO}$ injection after it was found to be injecting at a lower than expected rate. The $\mathrm{CO}$ concentration in the test chamber was found to be within the expected range after adjusting the flow.

Despite these anomalies, the contaminant injection system provided a total contaminant load as summarized by Table 5 . The average hourly injection of contaminants for the 624-hour test was actually very close to the specified rates listed by Table 2.

OVERALL TEST ASSESSMENT - During the TPCT, the TCCS performed electrically and mechanically without incident. All TCCS components performed within requirements; however, the methane single pass removal efficiency was lower than expected. It was measured at $55 \%$ rather than the expected greater than $90 \%$.

Table 4. Required versus Observed Test Conditions

\begin{tabular}{|l|c|c|}
\hline PARAMETER & REQUIREMENT & $\begin{array}{c}\text { OBSERVED } \\
\text { TEST } \\
\text { CONDITION }\end{array}$ \\
\hline Temperature & $\begin{array}{c}18.3-26.7^{\circ} \mathrm{C} \\
\left(65-80^{\circ} \mathrm{F}\right)\end{array}$ & $\begin{array}{c}21.6-23^{\circ} \mathrm{C} \\
\left(71-73^{\circ} \mathrm{F}\right)\end{array}$ \\
\hline Pressure & $750-786 \mathrm{~mm} \mathrm{Hg}$ & $751-780 \mathrm{~mm} \mathrm{Hg}$ \\
\hline Relative Humidity & $25-70 \%$ & $49-53 \%$ \\
\hline
\end{tabular}

Table 5. Contaminant Loading Summary

\begin{tabular}{|c|c|c|}
\hline COMPOUND & $\begin{array}{c}\text { TOTAL } \\
\text { MASS } \\
\text { INJECTED } \\
\text { (mg) }\end{array}$ & $\begin{array}{c}\text { AVERAGE } \\
\text { INJECTION } \\
\text { RATE } \\
(\mathrm{mg} / \mathrm{h})\end{array}$ \\
\hline ethanol & $15,444.5$ & 24.8 \\
\hline methanol & $2,615.7$ & 4.2 \\
\hline 2-propanol & $7,602.9$ & 12.2 \\
\hline n-butanol & $9,133.2$ & 14.6 \\
\hline toluene & $3,775.3$ & 6.0 \\
\hline xylene & $7,004.9$ & 11.2 \\
\hline chlorobenzene & $2,931.8$ & 4.7 \\
\hline dichloromethane & $4,073.7$ & 6.5 \\
\hline $\begin{array}{c}\text { 1,1,2-trichloro- } 1,2,2- \\
\text { trifluoroethane }\end{array}$ & $35,938.4$ & 57.6 \\
\hline trichlorofluoromethane & $2,692.8$ & 4.3 \\
\hline methane & $23,082.3$ & 37.0 \\
\hline acetone & $6,928.4$ & 11.1 \\
\hline 2-butanone & $11,425.4$ & 18.3 \\
\hline 4-methyl-2-pentanone & $2,687.7$ & 4.3 \\
\hline cyclohexanone & $1,279.1$ & 2.0 \\
\hline carbon monoxide & $5,858.8$ & 9.4 \\
\hline ammonia & $41,525.9$ & 66.5 \\
\hline
\end{tabular}

\section{DISCUSSION OF RESULTS}

During the test, the TCCS trace contaminant removal performance was, in general, as expected and was found to be consistent with past TCCS test results. The following discussion summarizes the observed performance for trace contaminant removal. Specific attention is given to the key TCCS design drivers and those contaminants that broke through the charcoal bed.

CONTAMINANTS OF INTEREST - Key contaminants of interest for the test included methanol, dichloromethane, ammonia, carbon monoxide, and methane. Methanol was also of interest because of its potential for charcoal bed breakthrough early in the test. Dichloromethane was also of interest because of its potential for charcoal bed breakthrough in addition to its role as a TCCS design driver. Also of interest was the increase in methane concentration that can result from catalyst poisoning as dichloromethane breaks through the charcoal bed. Ammonia and carbon monoxide were considered key solely because they are TCCS design drivers.

PROCESS PERFORMANCE - During the test, methanol was the first contaminant to break through the charcoal bed. This breakthrough is shown by Figure 4. Late in the test, dichloromethane began to break through the charcoal bed as shown by Figure 5. Dichloromethane breakthrough was still in progress at the test's conclusion. The test duration was not sufficient to observe any additional contaminant breakthrough of the charcoal bed; therefore, all the other contaminants were maintained at steady concentrations as shown by Table 6 . This performance was consistent with a $100 \%$ single pass removal efficiency.

Figure 6 shows the TCCS's performance for ammonia removal. Ammonia was controlled to between 4 and $5 \mathrm{mg} / \mathrm{m}^{3}$. This result demonstrated $100 \%$ removal by the phosphoric acidtreated charcoal bed during the entire test. No ammonia breakthrough was observed.

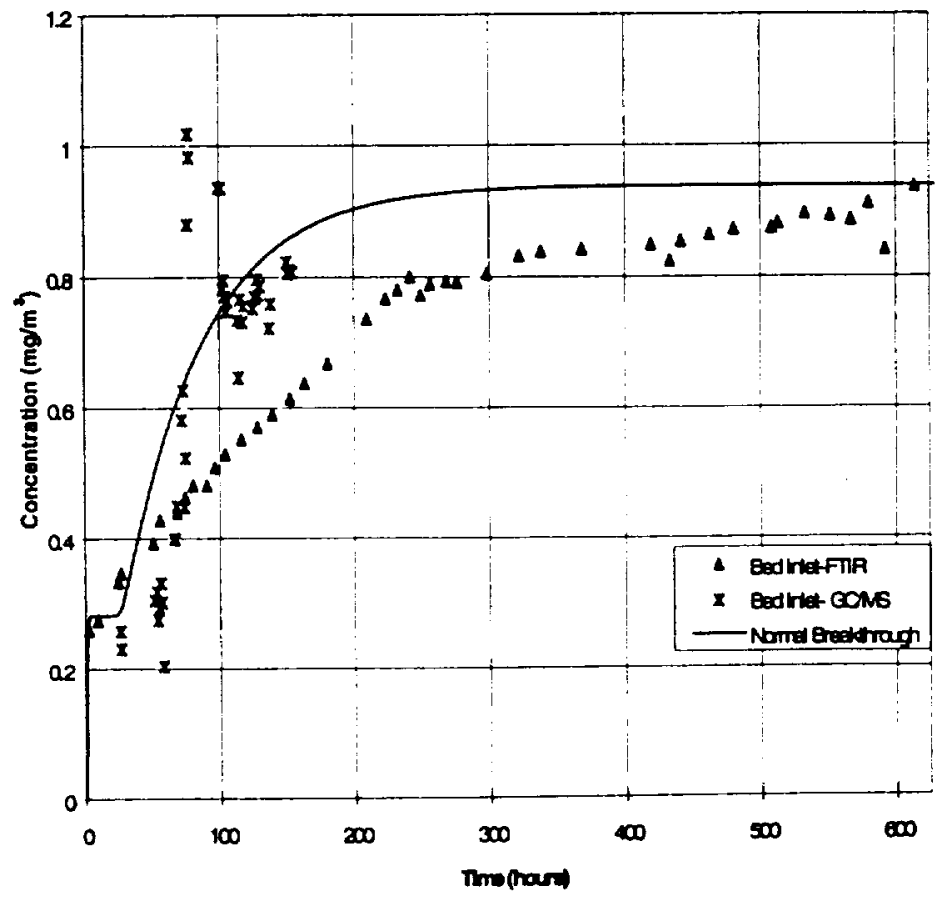

Figure 4. Methanol Concentration Trend 
Table 6. Observed Liquid Contaminant Concentrations

\begin{tabular}{|l|c|c|}
\hline \multirow{2}{*}{ COMPOUND } & \multicolumn{2}{c|}{ CONCENTRATION } \\
& \multicolumn{2}{|c|}{$\left(\mu \mathrm{g} / \mathrm{m}^{3}\right)$} \\
\cline { 2 - 3 } & OBSERVED & PREDICTED \\
\hline \multirow{2}{*}{ Ethanol } & 2250 & 1580 \\
& $+/-200$ & $+175 /-140$ \\
\hline \multirow{2}{*}{ Trichorotrifluoroethane } & 3530 & 3670 \\
& $+/-710$ & $+410 /-330$ \\
\hline Trichlorofluoromethane & 300 & 270 \\
& $+/-50$ & $+30 /-25$ \\
\hline Propanone & 700 & 710 \\
& $+/-40$ & $+80 /-65$ \\
\hline Propanol & 870 & 780 \\
& $+1-90$ & $+90 /-70$ \\
\hline Butanone & 1100 & 1170 \\
& $+/-90$ & $+130 /-110$ \\
\hline Butanol & 910 & 930 \\
& $+/-70$ & $+110 /-80$ \\
\hline Xylene & 610 & 715 \\
& $+/-50$ & $+80 /-65$ \\
\hline 4-Methyl-2-pentanone & 225 & 270 \\
\hline Toluene & $+/-20$ & $+30 /-25$ \\
\hline Chlorobenzene & 320 & 390 \\
\hline Cyclohexanone & $+/-30$ & $+40 /-35$ \\
\hline & 250 & 300 \\
& $+/ 20$ & $+35 /-30$ \\
\hline & 110 & 130 \\
& $+/-10$ & $+15 /-10$ \\
\hline
\end{tabular}

Methane was controlled to approximately $13 \mathrm{mg} / \mathrm{m}^{3}$ for the duration of test. Both samples collected at the TCCS inlet and just downstream of the charcoal bed (port 2) agreed well. This agreement demonstrated that methane is not removed by the activated charcoal. The methane concentration at the overall TCCS outlet (port 4 ) was consistently near $11 \mathrm{mg} / \mathrm{m}^{3}$ while the concentration downstream of the HTCO (port 3 ) was consistently near $6 \mathrm{mg} / \mathrm{m}^{3}$. A mass balance for methane based upon these results indicated a 55\% methane oxidation efficiency for the duration of the test. As shown by Figure 7, the concentration began to increase at approximately the time that di-

chloromethane breakthrough of the charcoal bed was observed.

The oxidation efficiency for carbon monoxide was $100 \%$ for the duration of the test. As shown by Figure 8, the concentration was controlled to approximately $1.2 \mathrm{mg} / \mathrm{m}^{3}$ during the first 250 hours of testing and then to approximately $2.5 \mathrm{mg} / \mathrm{m}^{3}$ for the remainder of the test. The low concentration early in the test was caused by a lower than required injection rate. This test facility anomaly was corrected and the injection was increased to within specification for the remainder of the test.

The only observed process-related anomaly involved methane. During the entire test, the oxidation efficiency provided by the HTCO was approximately 55\%. Two hypotheses have been proposed for this performance. The first is that the catalyst settled and allowed a portion of the air to bypass it. Because the HTCO design is kinetically limited with respect to the methane oxidation reaction, a small amount of air bypassing the catalyst could effectively reduce the reactor's residence time and, thus, lead to decreased efficiency.

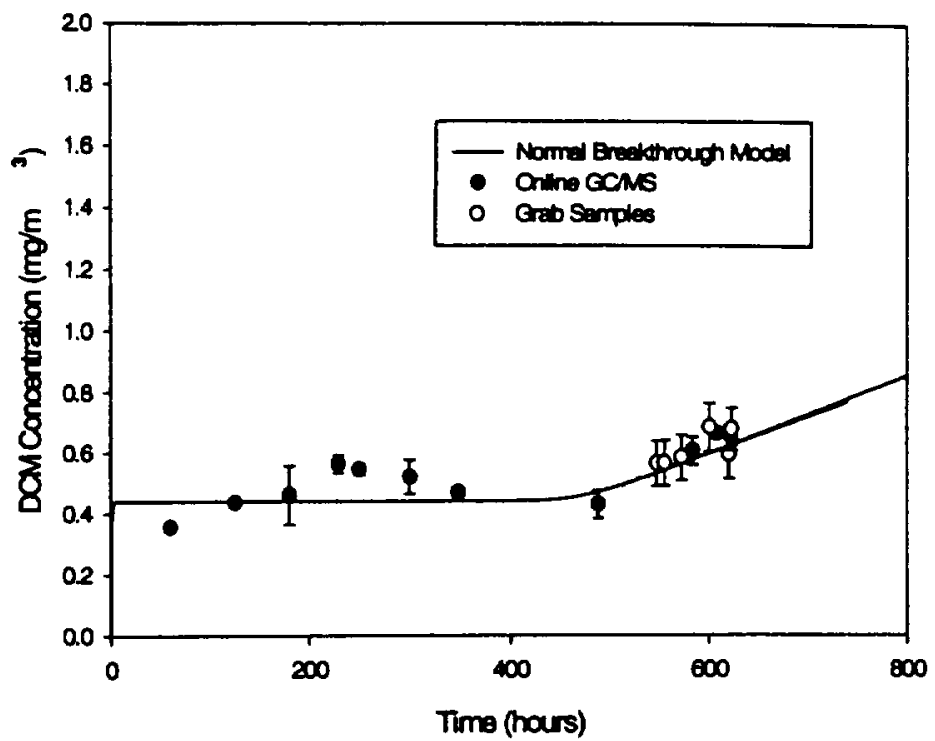

Figure 5. Dichloromethane Concentration Trend

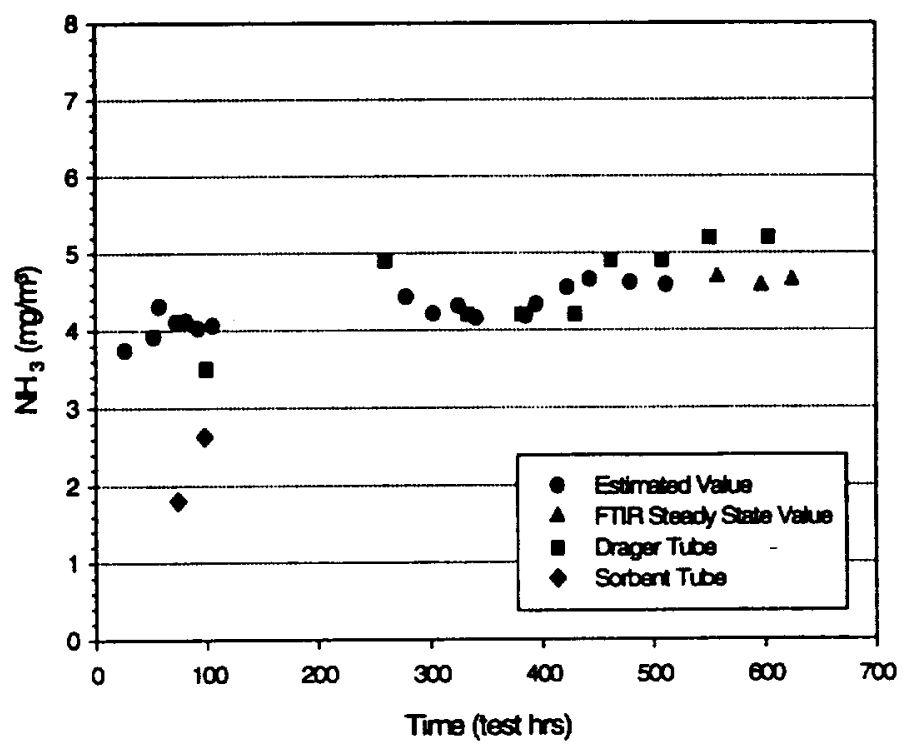

Figure 6. Ammonia Concentration

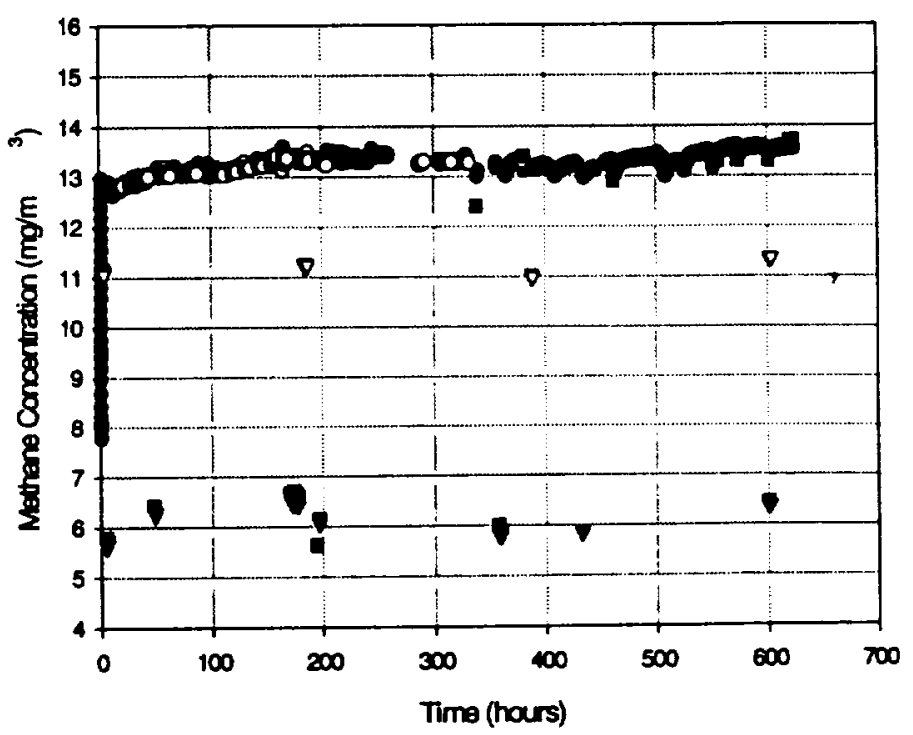

Figure 7. Methane Concentration 


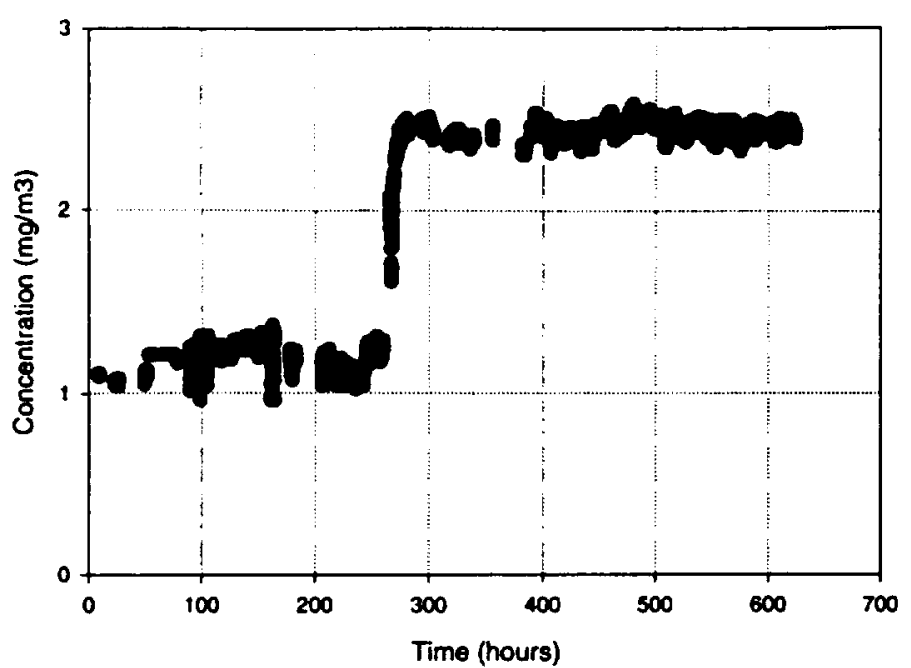

Figure 8. Carbon Monoxide Concentration

The second possibility is also related to the kinetic limitation. It involves masking of the catalyst surface. Inspection of TCCS drawings indicated that Dow Corning DC111 silicone grease had been used in the 7 duct couplings located between the charcoal bed outlet and the HTCO inlet. Offgassing of organosilicone compounds from this grease could have resulted in the formation of silica upon their oxidation. Silica has an extremely high melting point and once produced would immediately condense on the catalyst surface. Such a process would effectively mask or decrease the overall catalyst surface area leading to degraded methane oxidation efficiency.

It should be noted that carbon monoxide oxidation remained at $100 \%$ efficiency throughout the test. Since this reaction is diffusion limited rather than kinetically limited, it is quite possible for either a flow bypass or catalyst surface area reduction to have little measurable effect on the carbon monoxide oxidation reaction.

Final determination of the root cause for the degraded methane oxidation performance will be investigated before the TCCS is deployed on orbit. Despite this condition, the TCCS still has sufficient design margin to maintain the methane concentration well below SMAC.

COMPARISON TO MODEL PREDICTIONS - As stated earlier, one of the test objectives was to obtain data for process model validation. Central to this validation is the direct comparison of observed and predicted contaminant concentrations. A comparison of the observed and predicted concentrations for the liquid contaminants is provided by Table 6 .

As noted earlier, there were no breakthrough trends observed during the test which was consistent with $100 \%$ single pass removal predicted by the TCCS process model for each of these compounds. As such, a single test chamber average concentration describes the TCCS performance for removing these compounds. All observed contaminant concentrations were found to be statistically consistent with the predicted concentration confidence intervals with the exception of ethanol. The analytical instrument which was used to provide this result is biased high. The alternate analytical instrument gave an observation which was biased low (below projected concentration). As such it was assumed that the high ethanol concentration has no physical significance in terms of ethanol removal during the test period.
Both carbon monoxide and ammonia concentrations were reliably predicted by the process model. Both were consistent with $100 \%$ removal efficiency by the HTCO and charcoal bed, respectively.

Predicting methanol and dichloromethane concentration as they break through the charcoal bed was considered to be the most significant challenge to process model validation. As shown by Figures 4 and 5 , both methanol and dichloromethane breakthrough trends were reliably predicted. At the same time, the methane concentration trend during the time of dichloromethane breakthrough shown by Figure 7 was also found to be consistent with process model predictions.

These results are similar to those documented by Reference 40. In that case and in the case of the TPCT, the process model predicted contaminant concentrations within an acceptable statistical range. Based upon the comparison of predicted and observed concentrations for the TPCT combined with their similarity to previous validation study results, the process model is considered to provide highly reliable predictions of TCCS performance.

\section{CONCLUSIONS}

Based upon the results of the TPCT, conclusions which can be made are the following:

1. The TCCS design provides trace contaminant control for the load specified by the ISS Program.

2. Flight hardware performance is similar to that observed during previous development testing.

3. The TCCS design is robust and provides sufficient margin to accommodate lower than expected HTCO methane oxidation performance without approaching the SMAC.

4. The process model is a reliable tool for predicting TCCS performance over time.

\section{SUMMARY}

The ISS U.S. Habitation Module TCCS was challenged with a representative trace contaminant load for 624 hours. During this time, methanol and dichloromethane broke through the activated charcoal bed. The approximate time of breakthrough for each contaminant was consistent with pre-test process model predictions. In parallel with dichloromethane breakthrough, the methane concentration began to rise as a result of catalyst poisoning. This indicates a gradual poisoning of the methane oxidation reaction by dichloromethane's oxidation products. This effect is consistent with previous observations during TCCS development and bench scale testing. ,

Overall, the TCCS operated flawlessly. There were no mechanical or control anomalies noted for the flight hardware. Each trace chemical contaminant was controlled to less than its respective SMAC and performance was consistent with earlier TCCS development testing. One exception was a lower than expected methane oxidation efficiency provided by the HTCO during the entire test. Hypotheses have been prepared to explain this observation. Final determination of the root cause is to made during post-test evaluation of the hardware. In spite of this performance deficiency, methane never approached its SMAC. 


\section{ACKNOWLEDGMENT}

The authors extend their sincere appreciation to D. Rather, S. Manuel, and E. Cramblit of Boeing for their expert contributions to designing and operating the contaminant injection and in-line monitoring systems. Because this test involved flight hardware, a 3-shift operating schedule was implemented. Appreciation is extended to M. Vaden, G. Griffin, and J. Keller of Boeing and J. Knox, R. Erickson, and C. Ray of NASAMSFC for helping staff the test shifts.

\section{REFERENCES}

1. Wieland, P.O.: Designing for Human Presence in Space: In Introduction to Environmental Control and Life Support Systems. NASA RP-1324. NASA George C. Marshall Space Flight Center: MSFC, AL; 1994, pp. 101-107.

2. Design and Fabrication of a Trace Contaminant Removal System for Apollo. Phase I Report, NASA Contract NAS93415. Lockheed Missiles and Space Co., Inc.: Sunnyvale, CA, March 15, 1965.

3. Design and Fabrication of a Trace Contaminant Removal System for Apollo. Phase II Report, NASA Contract NAS9-3415. Lockheed Missiles and Space Co., Inc.: Sunnyvale, CA, November 23, 1965.

4. Design and Fabrication of a Trace Contaminant Removal System for Apollo. Phase III Report, NASA Contract NAS9-3415. Lockheed Missiles and Space Co., Inc.: Sunnyvale, CA, April 14, 1966.

5. Auerbach, E.E. and Russell, S.: New Approaches to Contaminant Control in Spacecraft. Atmosphere in Space Cabins and Closed Environments. K. Kammermeyer, editor. Meredith Publishing Co.: New York; 1966, pp. 145170.

6. Trade-off Study and Conceptual Designs of Regenerative Advanced Integrated Life Support Systems (AILSS). NASA CR-1458. NASA Contract NAS1-7905. Hamilton Standard Division of United Aircraft Corp.: Windsor Locks, CT; 1968, pp. 253-284.

7. Olcott, T. M.: Study and Preliminary Design of an IsotopeHeated Catalytic Oxidizer System. NASA CR-66346, NASA Contract NAS1-6256. Lockheed Missiles and Space Co., Inc.: Sunnyvale, CA; 1969.

8. Robell, A. J.; Arnold, C.R.;Wheeler, A.; Kersels, G. J.; and Merrill, R. P.: Trace Contaminant Adsorption and Sorbent Regeneration. NASA CR-1582. Lockheed Missiles and Space Co.: Palo Alto, CA; September 1970.

9. Olcott, T.; Lamparter, R.; Main, B.; Weitzmann, A.; Luce, R.: Olivier, G.; Kawasaki, E.; Masi, O.; Richardi, C.; and Selle, J.: Design, Fabrication, and Test of a Trace Contaminant Control System. LMSC-D462467. NASA Contract NAS1-11526. Lockheed Missiles and Space Co., Inc.: Sunnyvale, CA: November 28, 1975.

10. Link, D. E. and Angeli, J. W.: A Gaseous Trace Contaminant Control System for the Space Station Freedom Environmental Control and Life Support System. SAE 911452. Society of Automotive Engineers: Warrendale, PA; July 1991, pp. 2-4.

11. Olcott, T. M.: Design, Fabrication, and Test of A Trace Contaminant Control System. LMSC-D462467. NASA
Contract NAS 1-1 1526. Lockheed Missiles and Space Co., Inc.: Sunnyvale, CA: November 28, 1975, pp. 215-289.

12. Schunk, R.G.; Bagdigian, R.M.; Carrasquillo, R.L.; Ogle, K.Y.; and Wieland, P.O.: Space Station ECLSS Simplified Integrated Test. NASA Technical Memorandum 100363. NASA George C. Marshall Space Flight Center: MSFC, Alabama; March 1989.

13. Schunk, R.G.; Bagdigian, R.M.; Carrasquillo, R.L.; Ogle, K.Y.; and Wieland, P.O.: Space Station CMIF Extended Duration Metabolic Control Test Final Report. NASA Technical Memorandum 100362. NASA George C. Marshall Space Flight Center: MSFC, Alabama; March 1989.

14. Roberts, B.C.; Carrasquillo, R.L.; DuBiel, M.Y.; Ogle, K.Y.; Perry, J.L.; and Whitley, K.M.: Space Station Freedom Environmental Control and Life Support System Phase III Simplified Integrated Test Detailed Report. NASA Technical Memorandum 4204. NASA George C. Marshall Space Flight Center: MSFC, Alabama; May 1990.

15. Perry, J.L.; Space Station Freedom Environmental Control and Life Support System Phase III Simplified Integrated Test Trace Contaminant Control Subsystem Performance. NASA Technical Memorandum 4202. NASA George C. Marshall Space Flight Center: MSFC, Alabama; October 1990.

16. Perry, J.L.; Franks, G.D.; and Knox, J.C.: International Space Station Program Phase III Integrated Atmosphere Revitalization Subsystem Test Final Report. NASA Technical Memorandum 108541. NASA George C. Marshall Space Flight Center: MSFC, Alabama; August 1997.

17. Tatara, J.D. and Perry, J.L.: International Space Station Alpha Trace Contaminant Control Subassembly Life Test Final Report. NASA Technical Memorandum 108488. NASA George C. Marshall Space Flight Center: MSFC, Alabama; March 1995.

18. Perry, J.L.: Revised Requirements for the International Space Station Trace Contaminant Injection Test. NASA Internal Memorandum ED62(16-97). NASA George C. Marshall Space Flight Center: MSFC, Alabama; January 30, 1997.

19. Graves, J.; Joiner, C.; Peterson, B.; and Underwood, S.: Atmosphere Revitalization Predevelopment Operational Systems Test Report. T683-80026-1. Boeing Defense and Space Group: Huntsville, Alabama; June 12, 1992.

20. Trace Contaminant Control Subassembly Development Unit System Functional Test Report. LMSC/P024962. Lockheed Missiles and Space Co., Inc.: Sunnyvale, California; July 29, 1992.

21. Olcott, T.; Lamparter, R.; Main, B.; Weitzmann, A.; Luce, R.; Olivier, G.; Kawasaki, E.; Masi, O.; Richardi, C.; and Selle, J.: Design, Fabrication, and Test of a Trace Contaminant Control System. LMSC-D462467. NASA Contract NAS-1-11526. Lockheed Missiles and Space Co., Inc.: Sunnyvale, California; November 28, 1975.

22. Zeppa, S. J.: Trace Contaminant Control Subassembly (TCCS) Development Unit System Functional Test Report. LMSC/P024962. Lockheed Missiles and Space Co., Inc.: Sunnyvale, California; July 29, 1992.

23. Gully, A. J.; Bethea, R. M.; Graham, R. R.; and Meador. M. C.: Removal of Acid Gases and Oxides of Nitrogen from Spacecabin Atmospheres. NASA CR-1388. NASA 
Contract NAS 1-7584. Texas Technological College: Lubbock, Texas.

24. Wright, J. D.; Chen, B.; and Wang, C. M.: Trace Contaminant Oxidation Catalyst Poisoning Investigation. NASA Contract NAS8-38250-15. TDA Research, Inc.: Wheat Ridge, Colorado; March 22, 1996.

25. Leban, M. I.; Kawasaki, E. H.; and Conine, G. P.: Performance Characterization of Activated Carbon and Oxidation Catalyst for Gaseous Trace Contaminant Control. SAE 911548. Society of Automotive Engineers: Wartendale, PA; July 1991.

26. Lewis, W.K.; Gilliland, E.R.; Chertow, B.; and Cadogan, W.P.: "Pure Gas Isotherms." Industrial and Engineering Chemistry. Vol 42, No. 7, 1950, pp. 1326-1332.

27. Robell, A.J.; Arnold, C.R.;Wheeler, A.; Kersels, G. J.; and Merrill, R. P.: Trace Contaminant Adsorption and Sorbent Regeneration. NASA CR-1582. Lockheed Missiles and Space Co.: Palo Alto, CA; September 1970.

28. Olcott, T.M.: Development of a Sorber Trace Contaminant Control System Including Pre- and Post-Sorbers for a Catalytic Oxidizer. NASA CR-2027. Lockheed Missiles and Space Co.: Sunnyvale, CA; May 1972.

29. Olcott, T.M.: Design, Fabrication, and Test of A Trace Contaminant Control System. LMSC-D462467. NASA Contract NAS1-1 1526. Lockheed Missiles and Space Co., Inc.: Sunnyvale, CA; November 28, 1975.

30. Jagow, R.B.: Development of a Computer Program for Spacelab Contaminant Control Analysis. LMSC-D556710. NASA Contract NAS8-31551. Lockheed Missiles and Space Co., Inc.: Sunnyvale, CA; January 15, 1977.

31. Ray, C..D. and Stanley, J.B.: Spacelab Baseline ECS Trace Contaminant Removal Test Program. NASA TM-78135. NASA, George C. Marshall Space Flight Center, Marshall Space Flight Center, AL; September 1977.

32. Jagow, R.B.: Development of a Computer Program for Spacelab Contaminant Control Analysis. LMSC-D556710. NASA Contract NAS8-31551. Lockheed Missiles and Space Co., Inc.: Sunnyvale, CA; January 15, 1977, pp. 6771.

33. Ray, C.D.; Littles, J.W.; Blair, J.L.; and Jagow, R.B.: Design and Development of a Trace Contaminant Removal Canister for Spacelab. ASME 79-ENAs-16. $9^{\text {th }}$ Intersociety Conference on Environmental Systems. American Society of Mechanical Engineers: New York; July 1979.

34. Lamparter, R.L.: A Generalized Computer Program for Trace Contaminant Control. LMSC-D564045. NASA Contract NAS8-32400. Lockheed Missiles and Space Co., Inc.: Sunnyvale, CA; September 1, 1977.

35. Preliminary Documentation for Space Station Gaseous Contaminant Control Program. NASA Contract NAS836406. Bioastronautics Division, Lockheed Missiles and Space Co., Inc.: Sunnyvale, CA; September 5, 1986.

36. Perry, J.L.: Computerized Atmospheric Trace Contaminant Control Simulation for Manned Spacecraft. NASA TM108409. George C. Marshall Space Flight Center, Marshall Space Flight Center, AL; June 1993.

37. Perry, J.L.: A Users' Guide to the Trace Contaminant Control Simulation Computer Program. NASA TM-108456. NASA George C. Marshall Space Flight Center: MSFC, AL; April 1994.
38. Perry, J.L.: Trace Contaminant Control Simulation Computer Program-Version 8.1. NASA TM-108457. NASA George C. Marshall Space Flight Center: MSFC, AL; May 1994.

39. Perry, J. L. Validation of the Trace Contaminant Control Simulation Computer Program and Its Use for Supporting Flight Hardware Qualification. NASA Internal Memorandum ED62(39-95). NASA Marshall Space Flight Center: MSFC, Alabama; June 23, 1995.

40. Prime Item Development Specification for United States Laboratory, International Space Station. S683-29523D. Boeing Defense and Space Group: Huntsville, Alabama; March 28, 1995, pp. 109-115, 191.

41. Trace Contaminant Control Subassembly (TCCS). D68310008J. Boeing Defense and Space Group: Huntsville, Alabama; p. 66.

42. Alexandre, K.L.: Trace Contaminant Control Subassembly Performance Confirmation Test Preparation, Restoration, and Detailed Procedures. D495-51019-1. Boeing Defense and Space Group: Huntsville, Alabama; October 10, 1997.

43. Curtis, R.E.; Perry, J.L.; and Abramov, L.H.: Performance Testing of a Russian Mir Space Station Trace Contaminant Control Assembly. SAE 972267. Society of Automotive Engineers: Warrendale, PA; July 1997.

44. Perry, J.L.: International Space Station Trace Contaminant Control Subassembly Performance Confirmation Pretest Analysis. NASA Memorandum ED62(102-97). NASA, George C. Marshall Space Flight Center: MSFC, Alabama; December 16, 1997.

45. Sutton, N.: Variables Search - A Simple Technique for Spotting the Key Parameters. Chemical Engineering. August 1997, pp. 106-109.

46. Taguchi, G.: Taguchi on Robust Technology Development. ASME Press: 1993.

47. Box, G.E.P.; Hunter, W.G.; and Hunter, J.S.: Statistics for Experimenters. John Wiley and Sons, Inc.: 1978.

48. Hicks, C.R.: Fundamental Concepts in the Design of Experiments. Hold, Rinehart, and Winston: 1973. 